\title{
POINT-COUNTERPOINT
}

\section{The management of high-risk, locally advanced, prostate cancer radiation therapy}

\author{
Swetha Sridharan, BSc, MBBS, FRANZCR; Padraig Warde, MB, MRCPI, FRCPC \\ Department of Radiation Oncology, University of Toronto and the Radiation Medicine Program, Princess Margaret Cancer Centre, Toronto, ON
}

Cite as: Can Urol Assoc J 2012;6(5):393-5. http://dx.doi.org/10.5489/cuaj.12260

$\mathrm{P}$ rostate cancer is a common malignancy with 913000 new cases and 215000 deaths worldwide in 2008. ${ }^{1}$ Risk stratification systems are widely used to assist with patient counselling and guide treatment selection risk, as well to ensure prognostic uniformity in clinical trials and in the evaluation of treatment outcomes. Based on work by D'Amico and colleagues, the Genitourinary Radiation Oncologists of Canada (GUROC) developed a classification system for patients with localized/locally advanced disease based on T category, prostate-specific antigen (PSA) level at diagnosis and Gleason score. ${ }^{2,3}$ High-risk disease is defined as the presence of any of these factors: CT3 or CT4 category, PSA $>20 \mathrm{ng} / \mathrm{mL}$ or Gleason score $\geq 8$. Patients studied in clinical trials of "high-risk prostate cancer" represent a very heterogeneous group; this group includes patients with clinically organ-confined disease (cT1/T2) with high Gleason score, and/or PSA and also those with locally advanced disease.

In the landmark EORTC (European Organisation for Research and Treatment of Cancer) 22863 trial, overall survival (OS) and local control were considerably improved with the use of 3 years of adjuvant androgen deprivation therapy (ADT) when given with external beam radiotherapy (EBRT) in patients with high-risk locally advanced disease $\left(90 \%\right.$ had cT3/T4). ${ }^{4}$ With a median follow-up of 9.1 years, the survival advantage for combination treatment was substantial with a 10 -year OS of $58 \%$ in the combined treatment group compared with $40 \%$ in the radiotherapy (RT)-only group. However, despite the fact that combined modality treatment was superior to RT alone, the value of local treatment with RT remained under question as it was felt that the benefit seen may have been due to the early introduction of ADT. This has now been explored in three randomized trials (Table 1)..$^{5-7}$ The National Cancer Institute of Canada (NCIC) PR3/ Canadian Urologic Oncology Group
(CUOG)/Medical Research Council (MRC) UK PR07 study randomized 1205 patients with high-risk, locally advanced disease to treatment with combined modality therapy (RT and lifelong ADT) or treatment with ADT alone. ${ }^{5}$ With a median follow-up of 6 years, combined modality treatment resulted in a $23 \%$ reduction in overall mortality and a $46 \%$ reduction in disease-specific mortality (Fig. 1). There was a $70 \%$ reduction in disease progression with the addition of RT, and local disease progression as a first manifestation of overall progression was reduced from $39 \%$ to $15 \%$. The side effects of RT were of modest clinical magnitude and serious long-term genitourinary or gastrointestinal toxicity was uncommon. Patient-reported outcomes also showed that the negative impact of RT on bowel function was of modest clinical magnitude, with recovery scores matching those of patients without RT by 36 months. ${ }^{8}$

Similar data have been reported by Widmark and colleagues in the SPCG-7 study; 875 patients with prostate cancer were randomized to endocrine therapy alone or endocrine therapy and EBRT. ${ }^{6}$ With a median follow-up of 7.6 years, the cumulative incidence at 10 years for prostate-cancer-specific mortality was $23.9 \%$ in the endocrine alone group and $11.9 \%$ in the endocrine plus RT group. At 10 years, the cumulative incidence for overall mortality was $39.4 \%$ in the endocrine alone group and $29.6 \%$ in the endocrine plus RT group for a relative risk of death of 0.6. Urinary, rectal and sexual problems were slightly more frequent in the endocrine plus RT group. About $80 \%$ of patients in this study had locally advanced disease. Although this trial, like the NCIC PR3/MRC-UK PR07 study, addressed the issue of impact of RT on survival, there were some differences between the studies. Patients in the SPCG-7 trial had a favourable prognosis. The maximum allowable PSA for trial entry was $70 \mathrm{ng} / \mathrm{ml}$ and patients with PSA $>11 \mathrm{ng} / \mathrm{mL}$ were surgically staged and those with positive pelvic nodes on histological examination were excluded from the study. There were also some differences in the treatment between 


\begin{tabular}{|c|c|c|c|c|c|}
\hline Study & No. patients & Median follow-up & PFS: ADT vs. ADT+RT & DSS: ADT vs. ADT+RT & OS: ADT vs. ADT+RT \\
\hline Warde et al. ${ }^{13}$ & 1205 & 6 years & $\begin{array}{c}\mathrm{HR} 0.3,95 \% \mathrm{Cl} 0.23-0.39 \\
p=0.001\end{array}$ & $\begin{array}{c}\mathrm{HR} 0.54 \mathrm{Cl} 0.27-0.78 \\
\quad p=0.0001\end{array}$ & $\begin{array}{c}\mathrm{HR} 0.77,95 \% \mathrm{Cl} 0.61-0.98 \\
p=0.03\end{array}$ \\
\hline Widmark et al. ${ }^{14}$ & 875 & 7.6 years & $26 \%$ vs. $75 \% p=0.0001$ & $76 \%$ vs. $88 \% p<0.0001$ & $61 \%$ vs. $70 \%$ \\
\hline Mottet et al. ${ }^{15}$ & 264 & 5.6 years & $9 \%$ vs. $61 \% p<0.0001$ & $86 \%$ vs. $93 \% p=0.0586$ & $71.5 \%$ vs. $71.4 \% *$ \\
\hline
\end{tabular}

the two trials. In the SPCG-7 study, total androgen blockade was administered for the first 3 months followed by antiandrogen therapy until progression or death; in the $\mathrm{NCIC}$ PR3/MRC-UK PR07 study, hormonal therapy was ADT with lifelong luteinizing hormone releasing hormone analogue or bilateral orchiectomy.

Mottet and colleagues recently reported the results of a randomized phase III trial in which 264 patients, all with locally advanced disease, were randomized to ADT alone for 3 years or ADT and EBRT. ${ }^{7}$ With a median follow-up of 67 months, there was a marked improvement in locoregional control with the use of combined modality therapy (90.2\% vs. $70.8 \%$ with ADT alone). There was also a marked improvement in progression-free survival with the addition of EBRT ( $60.9 \%$ vs. $8.5 \%$ with ADT alone). However, likely due to the small sample size, no improvement in OS has been seen to date.

The dose of RT used in these trials (65-70 Gy) represented the standard of care in the 1990s when these trials were started. Over the past 15 years, the development of new RT techniques has allowed for a considerable increase in RT dose with acceptable morbidity in patients with localized prostate cancer. Multiple clinical trials have shown an improvement in local control and improved freedom from relapse with higher doses of radiation..$^{9-11}$ It is therefore likely that the improvement in survival seen with the addition of RT to ADT in these studies would be even more impressive with the use of modern RT dose fractionation schemes. In a single institution cohort study, Zelefsky and colleagues demonstrated that local control, as assessed by post-treatment biopsies, is improved with RT dose-escalation. ${ }^{12}$ Local tumour control was associated with a decrease in distant metastases and prostate cancer mortality - again, this emphasizes the importance of achieving optimal local control in these patients.

While dose escalation techniques with megavoltage EBRT have evolved greatly in recent years, rectal dose constraints limit the total dose of EBRT that can be administered. This makes dose escalation using brachytherapy an attractive option. A randomized trial by Sathya and colleagues compared the efficacy of an iridium implant plus EBRT versus EBRT alone in patients with T2/T3 disease. ${ }^{13}$ The 104 patients (40\% cT3) were randomized into 2 groups: (1) 51 received iridium implant of 35 Gy delivered to the prostate over 48 hours plus 40 Gy EBRT delivered at 2 Gy/fraction over 4 weeks and (2) 54 patients were randomized to EBRT alone of 66 Gy in 33 fractions. After a median follow-up of 8.2 years, the rates of biochemical failure were $29 \%$ in the implant and EBRT group versus $61 \%$ in the EBRT alone group. Local control was also better in the combined treatment group ( $51 \%$ vs. $24 \%$ ). However, the dose of EBRT used in this study was low by modern day standards. While dose escalation using brachytherapy in locally advanced disease may well be effective, there is insufficient data available at

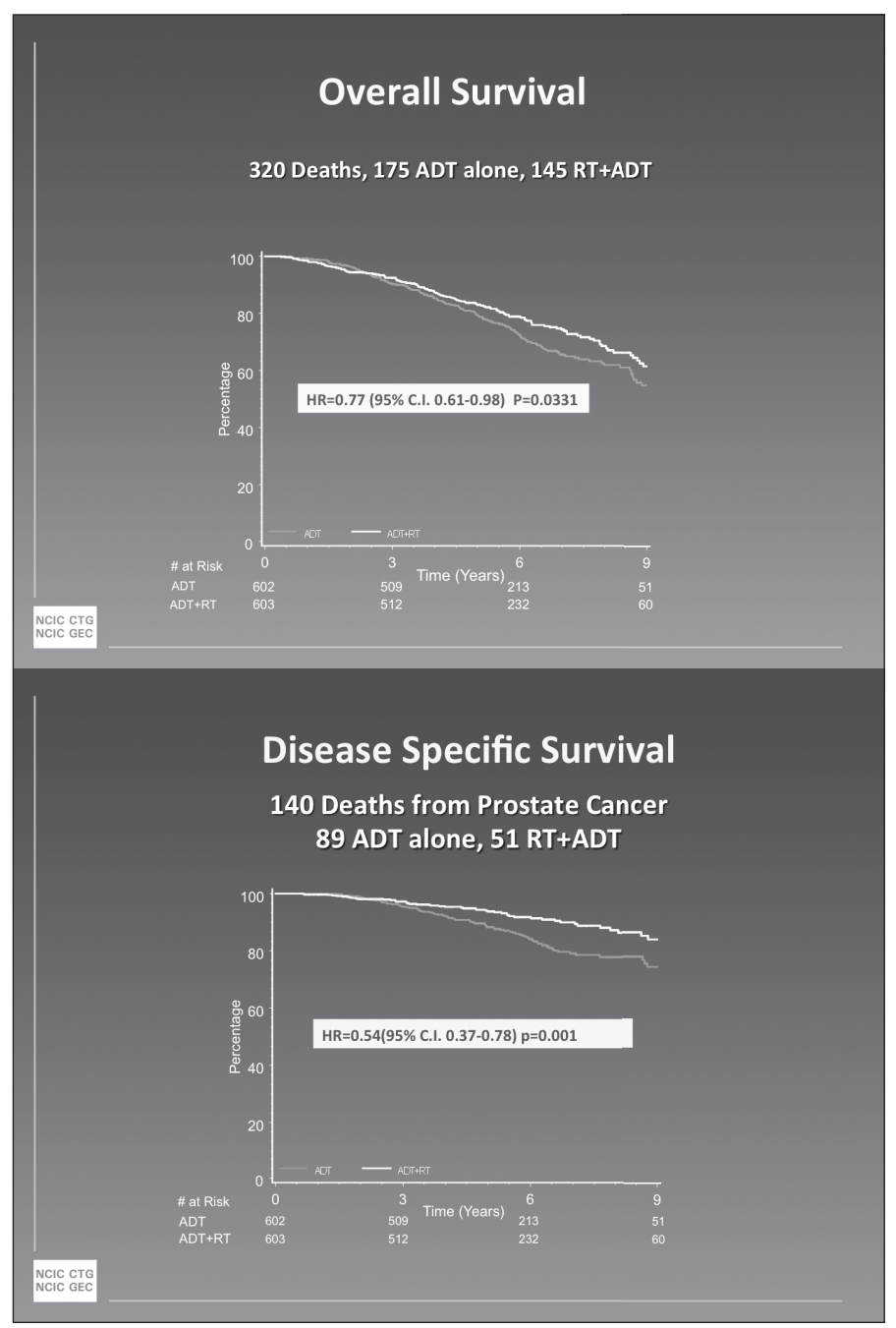

Fig. 1. Kaplan-Meier Curves for overall and disease-specific survival by treatment arm - PR3 study. Reproduced with permission from The Lancet. ${ }^{5}$ 
present to recommend this approach outside of a clinical research setting.

The heterogeneous nature of patients with high-risk locally advanced disease makes definitive statements regarding optimal management of this group of patients very difficult to make. Patients with localized disease with a high Gleason score and/or moderately elevated PSA may benefit from local treatment approaches other than RT. However, there is now mature level 1 evidence from multiple randomized trials that improved local control using EBRT in addition to ADT in patients with locally advanced prostate cancer improves overall and disease-specific survival. No such data exist for any other local treatment modality, such as surgery, and therefore in this era of evidence-based medicine EBRT combined with ADT remains the treatment of choice in this group of patients.

Competing interests: None declared.

This paper has been peer-reviewed.

\section{References}

1. Ferlay J, Shin HR, Bray F, et al. Estimates of worldwide burden of cancer in 2008: GLOBOCAN 2008. Int J Cancer 2008:127:2893-917. http://dx.doi.org/10.1002/iic.25516

2. Lukka H, Warde P, Pickles T, et al. Controversies in prostate cancer radiotherapy: consensus development. Can J Urol 2001:8:1314-22.

3. D'Amico AV, D'Amico AV, Whittington R, Malkowicz SB, et al. Biochemical outcome after radical prostatectomy, external beam radiation therapy, or intersitital radiation therapy for clinically localized prostate cancer. JAMA 1998;280:969-74. http://dx.doi.org/10.1001/jama.280.11.969
4. Bolla M, Van Tienhoven $G$, Warde $P$, et al. External irradiation with or without long term androgen suppression for prostate cancer with high metastatic risk: 10-year results of an EORTC randomised study. Lancet Oncol 2010;11:1066-73. http://dx.doi.org/10.1016/S1470-2045(10)70223-0

5. Warde $\mathrm{P}$, Mason M, Ding K, et al. Combined androgen deprivation therapy and radiation therapy for locally advanced prostate cancer: a randomised, phase 3 trial. Lancet 2011;378:2104-11. http://dx.doi. org/10.1016/50140-6736(11)61095-7

6. Widmark A, Klepp 0, Solberg A, et al. Endocrine treatment, with or without radiotherapy, in locally advanced prostate cancer (SPCG-7/SFU0-3): an open randomised phase 3 trail. Lancet 2009;373:301-8. http://dx.doi.org/10.1016/S0140-6736(08)61815-2

7. Mottet $\mathrm{N}$, Peneau $\mathrm{M}$, Mazeron JJ, et al. Addition of radiotherapy to long-term androgen deprivation in locally advanced prostate cancer: An open randomised phase 3 trial. Eur Urol 2012;62:213-9. htrp:// dx.doi.org/10.1016/i.eururo.2012.03.053

8. Brundage $M$, Parulekar $W$, Chen $B$, et al. The impact of Radiotherapy on Quality of Life when give in combination with ADT for locally advanced prostate cancer : QoL results from the NCIC CTG PR3/MRCPRO7 randomised trial. Radiother Oncol 2012;104:s73.

9. Zietman AL, Bae K, Slater J, et al. Randomized Trial Comparing Conventional-Dose With High-Dose Conformal Radiation Therapy in Early-Stage Adenocarcinoma of the Prostate: Long-Term Results From Proton Radiation Oncology Group/American College of Radiology 95-09. J Clin Oncol 2010;28:1106-11. http://dx.doi.org/10.1200/JC0.2009.25.8475

10. Kuban DA, Tucker $S$, Dong $L$, et al. Long-term results of the M.D Anderson randomized dose escalation trial for prostate cancer. IJROBP 2008;70:67-74.

11. Peeters $S$, Heemsbergen W D, Koper P, et al. Dose reponse in radiotherapy for localized prostate cancer: Results of the Dutch Multicenter Randomised Phase III trial comparing 68Gy of Radiotherapy with 78Gy. J Clin Oncol 2006;24:1990-6. http://dx.doi.org/10.1200/JC0.2005.05.2530

12. Zelefsky MJ, Reuter VE, Zvi F, et al. Influence of Local tumour Control on Distant metastases and Cancer related mortality after external beam radiotherapy for prostate cancer. J Urol 2008; 179:1368-73. http:// dx.doi.org/10.1016/i.juro.2007.11.063

13. Sathya JR, Davis IR, Julian JA, et al. Randomized trial comparing iridium implant plus external-beam radiation therapy with external beam radiation therapy alone in node-negative locally advanced cancer of the prostate. J Clin Oncol 2005;23:1192-9. hittp://dx.doi.org/10.1200/JC0.2005.06.154

Correspondence: Dr. Padraig Warde, Department of Radiation Oncology, Princess Margaret Cancer Centre, 610 University Ave., Toronto, ON M5G 2M9; fax: 416-946-4568; padraig.warde@rmp.uhn.on.ca 


\title{
Radical prostatectomy is the most cost-effective primary treatment modality for men diagnosed with high-risk prostate cancer
}

\author{
Yves Fradet, MD, FRCSC \\ Professor of Surgery/Urology, Université Laval, Québec, QC
}

T his year in Canada 26500 men will receive a diagnosis of prostate cancer and will be faced with the complex decision about the type and timing of primary treatment. In no other cancer is there such a lack of consensus about the optimal management of patients according to their risk category. Primary treatment offerings for prostate cancer vary from active surveillance, radical prostatectomy (RP), external-beam radiation therapy (EBRT), brachytherapy or androgen-deprivation therapy (ADT) and diverse guidelines draw no conclusion regarding the relative efficacy of these alternatives. The most important fear of a man diagnosed with prostate cancer is that of dying from the cancer after suffering from a protracted metastatic condition. Selecting a treatment modality that can best minimize these risks should be the priority, provided that the risk is well-understood by the patient.

D'Amico was the first to propose a simple risk classification based on pre-treatment criteria that could predict prostate cancer-specific mortality (PCSM) after primary treatment. ${ }^{1}$ This widely used classification defines high risk as Gleason 8-10 on biopsy or prostate-specific antigen (PSA) $>20$ or stage cT2C. Relative-to-low risk and intermediaterisk patients treated with RT or RP have a 5 -fold higher PCSM; similarly treated high-risk patients have a 14 -fold higher PCSM.

The opinion often expressed is that "RT and hormonal therapy are now the accepted standard treatments for patients with locally advanced prostate cancer because of the survival benefit shown in a randomized trial" (Level 1 evidence) comparing with RT alone. ${ }^{2}$ Ironically, this sentence comes from D'Amico in a 2003 publication which was the first to show, in intermediate- and high-risk groups treated during the PSA era, more than twofold higher PCSM in 2370 patients treated with modern RT compared to 4946 patients treated by RP, despite a significantly older population in the RT group (median 71.3 years in the RT group vs. 63.5 years in the RP group)..$^{1}$ In fact, surgery is the only treatment that has been compared to observation in a Swedish ${ }^{3}$ and a United States trial. ${ }^{4}$ The U.S. Prostate Cancer Intervention Versus Observation Trial showed no benefit of surgery overall, which is no surprise given that $>75 \%$ of patients had a low risk prostate cancer at randomization and a high 10- and 15-year mortality by any cause of $40 \%$ and $60 \%$, respectively. Despite these limitations, in the $20 \%$ of patients that had a Gleason $\geq 7, \mathrm{RP}$ reduced the PCSM by $60 \%$ (HR $0.4 \mathrm{CI} 0.16-1.0$ ) which should become significant with longer follow-up. Similarly, in an individualized estimation of the benefit of RP in the Scandinavian trial, Vickers and colleagues concluded that RP unequivocally benefits patients with Gleason 8 cancers or Gleason 7 and clinical stage T2 (2 of $3 \mathrm{D}^{\prime}$ Amico intermediate-risk factors). ${ }^{5}$

The CaPSURE (Cancer of the Prostate Strategic Urologic Endeavor) registry, that has monitored longitudinally the outcome of prostate cancer patients who received treatment at any of 40 (primarily community-based) urology practices across the U.S., shows that RP has been the primary treatment for $42 \%$ of patients with high-risk cancer. This proportion has not significantly changed between 1990 and 2007, while EBRT or brachytherapy went from $26 \%$ to $17.5 \%$ and ADT alone from $18.5 \%$ to $29 \% .{ }^{6}$ In Canada, our group has been advocating RP as a valuable treatment option for highrisk prostate cancer patients for a few decades. Our results, first reported in 2008 , showed that up to $25 \%$ of high-risk patients have organ-confined cancer at final pathology after $\mathrm{RP}$ and their 10-year biochemical recurrence (BCR) was $30 \%$ and PCSM 3.8\%.7 The 10-year BCR for the whole cohort of high-risk patients treated by RP was $65 \%$ and PCSM $10 \%$. As individual risk factors, PSA $>20$ was the least predictive of PCSM with only $4.5 \%$ at 10 years, compared to $9.2 \%$ for CT2c+ and $18.2 \%$ for Gleason $8+$. These outcomes seem highly reproducible between high-volume centres. In a recent report combining data on $>23000$ patients treated 
by RP at 5 academic U.S. institutions, the 10-year PCSM for Gleason 8 was also $18 \% .^{8}$

So, is there evidence that one treatment modality is superior at reducing PCSM? Short of any report on randomized studies across primary treatments, the best evidence to date comes from 6 observational studies - all of which have reported improved PCSM and/or overall survival among patients treated with RP compared to EBRT. A European study performed by epidemiologists showed a 2.3-fold increased PCSM in men treated by EBRT versus RP. ${ }^{9}$ They concluded that "surgery offers the best chance for long-term prostate cancer specific-survival, in particular for younger patients and patients with poorly differentiated tumors." In the same year, Albertsen and colleagues analysed outcomes of 1618 men in the Connecticut Tumor Registry who were diagnosed in the early PSA era, adjusting for D'Amico risk classification and comorbidity. ${ }^{10}$ Again, men treated by EBRT had a 2.2-fold increased PCSM compared to RP after a median follow-up of 13 years. Also in 2007, Tewari and colleagues reported outcomes of a large cohort of high-grade prostate cancer patients which showed a 54\% and 49\% lower all-cause and PCSM for patients treated by RP versus EBRT. ${ }^{11}$ In 2010, there were two important studies. The first study analyzed outcomes of 7538 men from the CaPSURE registry and showed that the PCSM relative to prostatectomy was 2.2 for EBRT and 3.2 for ADT. ${ }^{12}$ The authors concluded that "although this was not a randomized study, given the multiple adjustments and sensitivity analyses, it is unlikely that unmeasured confounding would account for the large observed difference in survival." The critiques will say that RT has improved and that results should be better in recent years. The second study by Zelefsky and colleagues reported the 8-year metastasis-free survival of a prospective cohort of 1318 patients treated by RP at Memorial Sloan-Kettering Cancer Center and 1062 treated by intensity-modulated radiation therapy (IMRT) delivering $>80$ Gy in all patients. ${ }^{13}$ $\mathrm{RP}$ reduced the risk of metastasis by $65 \%$ and the PCSM by $68 \%$. Finally, Kibel and colleagues recently reported on a cohort of 10429 patients treated between 1995 and 2005 at the St. Louis and Cleveland clinic with only $12 \%$ of patients being high risk. ${ }^{14}$ Using a propensity score analysis, EBRT was associated with a 1.6-fold risk of all-cause mortality and 1.5-fold risk of PCSM overall.

Thus it would seem appropriate to conclude that all patients facing the choice of treatment for high-risk prostate cancer should be informed that, based on available evidence, RP as primary treatment will reduce at least 2-fold their PCSM and risk of metastasis. Obviously, patients with BCR after RP can benefit from salvage EBRT. We recently reported similar long-term results on mortality and metastasis in patients with positive surgical margin treated with salvage EBRT at a median PSA $<0.5$ compared to patients with negative margins. ${ }^{15,16}$ Even when including the cost of salvage EBRT, RP remains significantly less expensive than EBRT for this group of patients, as more than one third of high-risk patients will not experience BCR and thus not receive ADT. In addition to a higher cost of the primary treatment, all patients treated with EBRT for high risk will receive at least 6 months of ADT in addition to long-term ADT upon BCR.

$\mathrm{RT}$ of prostate cancer is a moving target and several radiation therapists are now offering combined treatments that include brachytherapy, IMRT and ADT for high-risk patients on the basis that it allows the delivery of higher radiation dose levels to the prostate. These treatments should be presented as experimental, given the fact that despite previous increments in dose delivered to the prostate, the impact has not been translated into better PCSM compared to RP. One must also be cautious in judging the efficacy of EBRT on BCR as it has been recently shown that BCR after EBRT was associated with a 1.5-fold $(p=0.006)$ increase in PCSM compared to BCR after RP. ${ }^{17}$ Patients must also be aware of the nature and severity of potential complications with these "new" treatments. Finally, one must remember that radiation treatments can be associated with an increased risk of secondary cancers, particularly in patients with a long survival as is the case for most prostate cancer patients even with high-risk disease.

Competing interests: None declared.

This paper has been peer-reviewed.

\section{References}

1. D'Amico AV, Moul J, Carroll PR, et al. Cancer-specific mortality after surgery or radiation for patients with clinically localized prostate cancer managed during the prostate-specific antigen era. J Clin Oncol 2003;21:2163-72. http://dx.doi.org/10.1200/JC0.2003.01.075

2. Bolla $M$, Collette L, Blank L, et al. Long-term results with immediate androgen suppression and external irradiation in patients with locally advanced prostate cancer (an EORTC study): A phase III randomised trial. Lancet 2002;360:103-6. http://dx.doi.org/10.1016/50140-6736(02)09408-4

3. Bill-Axelson A, Holmberg L, Ruutu M, et al. Radical prostatectomy versus watchful waiting in early prostate cancer. N Engl J Med 201 1;364:1708-17. http://dx.doi.org/10.1056/NEJMoa1011967

4. Wilt TJ, Brawer MK, Jones KM, et al. Radical prostatectomy versus observation for localized prostate cancer. N Engl J Med 2012;367:203-13. htrp://dx.doi.org/10.1056/NEJMoal113162

5. Vickers A, Bennette C, Steineck G, et al. Individualized estimation of the benefit of radical prostatectomy from the Scandinavian Prostate Cancer Group Randomized Trial. Eur Urol 2012;62:204-9. http://dx.doi. org/10.1016/j.eururo.2012.04.024

6. Cooperberg MR, Cowan J, Broering JM, et al. High-risk prostate cancer in the United States, 1990-2007. World J Urol 2008;26:21 1-8. hittp://dx.doi.org/10.1007/s00345-008-0250-7

7. Lodde M, Harel F, Lacombe L, et al. Substratication of high-risk localised prostate cancer treated by radical prostatectomy. World J Urol 2008;26:225-9. htrp://dx.doi.org/10.1007/s00345-008-0252-5

8. Eggener SE, Scardino PT, Walsh PC, et al. Predicting 15-year prostate cancer specific mortality after radical prostatectomy. J Urol 2011;185:869-75. http://dx.doi.org/10.1016/i.juro.2010.10.057

9. Merglen A, Schmidlin F, Fioretta $G$, et al. Short- and long-term mortality with localized prostate cancer. Arch Intern Med 2007;167:1944-50. http://dx.doi.org/10.1001/archinte.167.18.1944 
Fradet

10. Albertsen PC, Hanley JA, Penson DF, et al. 13-year outcomes following treatment for clinically localized prostate cancer in a population based cohort. J Urol 2007;177:932-6. http://dx.doi.org/10.1016/j. juro.2006.10.051

11. Tewari A, Divine $G$, Chang P, et al. Long-term survival in men with high grade prostate cancer: a comparison between conservative treatment, radiation therapy and radical prostatectomy - a propensity scoring approach. J Urol 2007;177:911-5. http://dx.doi.org/10.1016/i.juro.2006.10.040

12. Cooperberg MR, Vickers AJ, Broering JM, et al. Comparative risk-adjusted mortality outcomes after primary surgery, radiotherapy, or androgen-deprivation therapy for localized prostate cancer. Cancer 2010;116:5226-34. htrp://dx.doi.org/10.1002/cncr.25456

13. Zelefsky MJ, Eastham JA, Cronin AM, et al. Metastasis after radical prostatectomy or external beam radiotherapy for patients with clinically localized prostate cancer: a comparison of clinical cohorts adiusted for case mix. J Clin Oncol 2010;28:1508-13. http://dx.doi.org/10.1200/JC0.2009.22.2265

14. Kibel AS, Ciezki JP, Klein EA, et al. Survival among men with clinically localized prostate cancer treated with radical prostatectomy or radiation therapy in the prostate specific antigen era. J Urol 2012;187:1259-65. htrp://dx.doi.org/10.1016/i.juro.2011.11.084
15. Mavermann J, Fradet V, Lacombe, L, et al. The impact of solitary and multiple positive surgical margins on hard clinical end points in 1712 adiuvant treatment-naive pT2-4 N0 radical prostatectomy patients. Eur Urol. In press.

16. Mavermann J, Fradet V, Fradet Y. Adjuvant versus Salvage Radiotherapy in Patients with Positive Surgical Margins at Radical Prostatectomy: that is the Question. Eur Urol. In press.

17. Lee BH, Stephenson AJ, Czieki J, et al. Comparison of observed prostate cancer-specific mortality by treatment-specific, nomogram-predicted risks of biochemical recurrence in men with localized prostate cancer treated by radical prostatectomy, external beam radiotherapy, or brachytherapy. J Urol 2011;185:e194 (Abst 476).

Correspondence: Dr. Yves Fradet, Centre de recherche, L'Hôtel-Dieu-de-Québec, 11 côte du Palais, Québec, QC GIR 2J6; y.frade†@diagnocure.com 